\title{
COMO OS MESTRANDOS APRENDEM? SIGNIFICADOS E TRANSFORMAÇÕES EM UM PROGRAMA DE PÓS-GRADUAÇÃO EM ADMINISTRAÇÃO
}

\author{
HOW MASTER'S DEGREE STUDENT'S LEARN? MEANINGS AND \\ TRANSFORMATIONS IN A GRADUATE MANAGEMENT SCHOOL
}

\author{
¿COMO LOS ESTUDIANTES DE MÁSTER APRENDEN? SIGNIFICADOS $Y$ \\ TRANSFORMACIONES EN UN PROGRAMA DE POSGRADO EN \\ ADMINISTRACIÓN
}

Thales Batista de Lima, Universidade Federal da Paraíba (PPGA), João Pessoa, PB, Brasil

Anielson Barbosa da Silva, Universidade Federal da Paraíba (PPGA), João Pessoa, PB, Brasil

Artigo Submetido em 19.10.2016. Ajustado e Aprovado em 22.12.2017.

Avaliado pelo processo de double blind review

e-mail para contato: anielson@uol.com.br

\begin{abstract}
RESUMO
Este artigo tem como objetivo compreender o processo de aprendizagem de mestrandos de um Programa de Pós-Graduação sob a perspectiva da aprendizagem transformadora. O percurso metodológico foi orientado por uma abordagem qualitativa, e utilizou entrevistas para captar os significados da aprendizagem de mestrandos. Os resultados indicam a presença de alguns elementos constitutivos envolvendo as perspectivas de significado, os domínios de aprendizagem e os tipos de reflexão, mas não se pode afirmar que o processo de aprendizagem dos mestrandos é transformador. Aspectos como o tempo de permanência no curso, a maturidade, o nível de autodirecionamento dos alunos, além de questões vinculadas ao ambiente de aprendizagem e o relacionamento entre os docentes e os mestrandos, atuam como fatores mediadores do processo de aprendizagem. 0 estudo revelou a necessidade de empreender ações que contribuam para a formação do professor e do pesquisador, a partir de uma avaliação das perspectivas de significado, os domínios de aprendizagem e os tipos de reflexão que podem ser incorporados no processo de ensino, nas relações professor-aluno e também a criação de um ambiente de aprendizagem que não considere apenas a dimensão física, mas também a comportamental, a social, a tecnológica e a política.
\end{abstract}

Palavras-Chave: Aprendizagem Transformadora; Pós-Graduação; Ambiente de aprendizagem; Administração.

\section{ABSTRACT}

This paper aims to understand the learning process of master's students of a graduate school from the perspective of transformative learning. The methodological path was advised by a qualitative approach, and used interviews to capture the meanings of learning of master's students. The results indicate the presence of some constituent elements involving the meaning perspectives, learning domains and types of reflection, but we can't say that the learning process of the master's students is transformer. Aspects such as the time spent in the master's degree course, the maturity, the self-direction of the students, in addition to issues linked to the learning environment and the relationship between professors and students, act as mediator's factors of the learning process. The study showed the need to undertake actions that contribute to the formation of professors and researchers, from an evaluation of the meaning perspectives, learning domains and types of reflection that can be incorporated into the process of teaching, professorstudent relations, and the creation of a learning environment that does not consider 


\section{(9)REUNIR}

only the physical dimension, but also the behavioral, social, technological and political.

Key-Words: Transformative Learning; Master's Degree Graduate; Learning environment; Management.

\section{RESUMO}

Este artículo tiene como objetivo comprender el proceso de aprendizaje de estudiantes de maestría de un programa de pos-grado a partir de la perspectiva del aprendizaje transformadora. La trayectoria metodológica fue orientada por un abordaje cualitativo, y utilizó entrevistas para captar los significados del aprendizaje de los estudiantes de maestría. Los resultados indican la presencia de algunos elementos constitutivos envueltos en las perspectivas de significado, los dominios de aprendizaje y los tipos de reflexión, pero no se puede afirmar que el proceso de aprendizaje de los alumnos es transformador. Aspectos como el tiempo de permanencia en el curso, la madurez, el nivel de autodirección de los estudiantes, además las cuestiones vinculadas al ambiente de aprendizaje y el relacionamiento entre los profesores e los alumnos, actúan como factores mediadores del proceso de aprendizaje. La investigación reveló la necesidad de emprender acciones que contribuyan para la formación de profesores $e$ investigadores, además de una evaluación de las perspectivas de significado, los dominios de aprendizaje y los tipos de reflexión que pueden ser incorporados en el proceso de enseñanza, en las relaciones profesor-alumno y también en la creación de un ambiente de aprendizaje que no consiste apenas en la dimensión física, pero también la comportamental, la social, la tecnológica y la política.

Palabras-Clave: Aprendizaje Transformadora; Pós-Grado; Ambiente de aprendizaje. Administración.

\section{INTRODUÇÃO}

Os estudos envolvendo a aprendizagem transformadora no campo da educação superior em Administração ainda são escassos, pois as pesquisas nesta temática envolvem mais outras áreas de conhecimento como a educação, psicologia e ciências da saúde, como demonstram as pesquisas de Lima (2011) e Lonie e Desai (2015). Outras áreas de conhecimento são mais privilegiadas nos estudos desta temática porque buscam um olhar atento aos desafios da educação frente à inércia comportamental dos estudantes (MCALLISTER, 2015). Os aprendizes adultos, em contraste com as crianças, são capazes de assumir a responsabilidade por seus comportamentos, suas ações e opiniões e, portanto, para a sua aprendizagem (ILLERIS, 2003). Os estudos sobre a aprendizagem, por vezes, são conduzidos ao campo gerencial ou empresarial, o que instiga a realização de estudos no campo da educação em administração que possam contribuir para o seu aprimoramento.

Os pressupostos dos estudos de Lindeman (1926) reforçam que a educação deve preparar os alunos e promover o seu crescimento para enfrentar os desafios da vida. Já Knowles (1980) introduziu o termo andragogia no campo da educação de adultos, reforçando a ideia de que os adultos estão dispostos a direcionar sua aprendizagem para o que é útil e necessário em suas vidas. Por sua vez, Freire (1981) introduz uma postura mais crítica sobre os programas de educação para adultos que mantinham as pessoas presas em 
sua estrutura de classe. Os professores e os alunos carecem de uma maior conscientização para se libertarem da opressão e impulsionarem um processo de pensamento crítico. Para Chapman (2007), John Dewey reforçou as bases para a educação de adultos - a experiência, a reflexão, o raciocínio e a democracia na educação no século passado.

A aprendizagem transformadora é uma perspectiva teórica que pode ser difundida na educação superior, pois focaliza como as pessoas aprendem por meio da transformação das perspectivas de significados atuais, para orientar suas ações futuras (CRANTON, 2006). Na educação de adultos, as pessoas trazem consigo experiências vivenciadas e suas próprias visões de mundo. Estas são impactadas com novas interpretações que alteram a sua perpectiva atual de significado, promovendo uma nova forma de enxergar uma situação que conduz a uma percepção diferente da que tinha anteriormente, ocorrendo, dessa forma, um processo de aprendizagem transformadora, a partir uma reflexão crítica e individual sobre a compreensão de si próprio (LIMA, 2011).

Na pós-graduação, o processo de aprendizagem pode ser significativo na formação acadêmica de mestrandos e doutorandos e pode possibilitar a compreensão da aprendizagem a partir de suas vivências. Este estudo objetivou compreender o processo de aprendizagem de mestrandos de um Programa de Pós-Graduação em Administração de uma Universidade Federal do Nordeste brasileiro a partir da perspectiva da aprendizagem transformadora.

Considera-se a investigação relevante em função da excessiva demanda de atividades de tais mestrandos do referido Programa que gera a indagação da capacidade reflexiva de assimilação dos conteúdos e como essa demanda de atividades propicia transformações significativas em seu aprendizado. Essas indagações são vivenciadas por educadores no meio acadêmico para encontrar progresso acadêmico a partir de alternativas que oportunizem uma aprendizagem transformadora, conforme relatos de pesquisas envolvendo a temática, como por exemplo Nye e Clarck (2016) que apontam a relevância de um aprendizado que conduza a reflexões, discussões e trabalhos que valorizem uma formação crítica, participativa e ativa do aluno; o de Westoby e Lyons (2017) ao abordarem o envolvimento dos alunos no pensamento analítico e na ação social em um contexto social conflituoso; e os estudos de Joubert e Slabbert(2017) sobre os desafios em avançar nesta forma de aprendizagem no ensino superior, pois a existência de dados empíricos sobre casos de aprendizagem transformadora implementados com sucesso são limitados.

O estudo traz três contribuições: a primeira envolve auxiliar os estudantes da pósgraduação a refletirem sobre o seu processo de aprendizagem e a segunda suscitar uma reflexão na coordenação e corpo docente do programa de pós-graduação avaliar a condução de seu planejamento pedagógico e das estratégias de ensino utilizada para o fomento de um processo de ensino-aprendizagem transformador formação de mestres em administração. Por fim, pode contribuir para o desenvolvimento de competências profissionais e acadêmicas para o exercício efetivo na área.

\section{REFERENCIAL TEÓRICO}

Muitas teorias de aprendizagem foram originalmente concebidas para auxiliar na compreensão do desenvolvimento da criança e informar o seu ensino, chamada de pedagogia. Contudo, há algumas abordagens quesão destinadas ao desenvolvimento de 


\section{(9)REUNIR}

adultos como a andragogia, pois percebem o aluno adulto como um participante ativo no processo de aprendizagem (CLARKE; BUTCHER, 2006). Segundo Beavers (2009), a andragogia se insere em um processo de aprendizagem e os aspectos do seu ambiente não só afetam o modo como as pessoas aprendem, mas a fonte de aprendizagem.

Esse trabalho se baseia na ideia proposta por John Dewey (2001) acerca da andragogia quando defende um ambiente de aprendizagem com um senso de hospitalidade, mais libertador na relação entre professor e aluno, cujo processo de ensino-aprendizagem afina tal relacionamento no intuito de promover interações sociais, felicidade e auto eficácia (KRAMER, 2016). Os educadores de adultos devem se esforçar para não serem vistos como "professores", mas como "facilitadores". Os docentes devem implementar novas tecnologias educacionais e se adaptarem a novos ambientes de ensino (LEE; BRETT, 2014), até porque o aprendizado transformador desafia as estratégias de ensino e o processo de avaliação mais tradicional, com mudanças de comportamento envolvendo cognição, estética, emoção e ética (PATTERSON ET AL, 2015).

De acordo com o estudo da década de 1980 de Knowles (1980), há uma mudança na prática educacional, deslocando o foco do ensino para a aprendizagem, com ênfase na educação como um processo facilitado na aprendizagem autodirecionada que demanda uma redefinição do papel do professor, que passa a apoiar o aluno em seu processo de aprendizagem, estimulando-o a buscar conhecimentos e descobrir novas experiências. Percebe-se, mais recente, conforme McAllister (2015), que o ensino continua sendo uma arte complexa que exige coragem para se comprometer, particularmente em face de estudantes estressados, currículos lotados, tensões em preparação para o papel de graduação e pós-graduação, além da escassez de educadores motivados com uma formação efetiva de seus alunos. Outro aspecto inserido no novo pensamento da educação em relação a uma prática moderna é a aprendizagem ao longo da vida (DEWEY, 2001). A premissa básica subjacente a esta linha de pensamento é que em um mundo de mudanças rápidas, se faz necessário que a aprendizagem seja um processo permanente e duradouro.

Ressalta-se que, conforme Merriam e Caffarella (1991), este tipo de aprendizagem autodirecionada depende de uma série de variáveis como, por exemplo, o ambiente da aprendizagem, o estímulo da pessoa em aprender, a capacidade de lidar com suas competências, a experiência com o conteúdo que será aprendido, entre outros fatores.Desse modo, Mezirow e seus associados (1990; 2009) desenvolveram a teoria da aprendizagem transformadora ao longo das últimas décadas com o objetivo de compreender como a aprendizagem emancipatória pode promover mudanças na construção da realidade pelas pessoas. Percy (2005) acrescenta que esta teoria tem crescido e mudado por quase três décadas, inspirada na sociologia, na filosofia, na psicologia cognitiva e do desenvolvimento e a psicoterapia.

Destaca-se que os estudos voltados à Teoria da Aprendizagem Transformadora têm celebrado quatro décadas, desde o início das pesquisas de Jack Mezirow até os recentes estudos de Taylor sobre o impacto dessa aprendizagem no contexto real da pessoa por meio de suas experiências e identidades. Diversos estudos especificaram públicos no âmbito educacional e empresarial, considerando as transformações de indivíduos, até então, marginalizados socialmente em termos de etnia, gênero, raça e distintas linguagens e culturas (KOKKOS ET AL, 2015). 


\section{(9)REUNIR}

A aprendizagem transformadora também objetiva transformar, de forma consciente, os quadros de referência dos indivíduos, por intermédio da reflexão crítica sobre pressupostos construídos de modo acrítico. Esta teoria envolve a aprendizagem em contextos formais e informais, dirigindo-se à interseção entre o individual e o social, dimensões coexistentes e igualmente importantes, já que as pessoas integram a sociedade e são determinantes para o seu desenvolvimento (CRANTON, 2006).

Mezirow (2000) sugere algumas fases que os adultos passam quando ocorre a aprendizagem transformadora. São elas:um dilema desorientador; um exame de consciência envolvendo sentimentos de medo, raiva, culpa ou vergonha; uma avaliação crítica das hipóteses; reconhecimento de que a própria insatisfação e o processo de transformação são compartilhados; a exploração de opções para novos papéis, relações e ações; o planejamento de um curso de ação; a aquisição de conhecimentos e habilidades para implantar os planos de ação; tentativa provisória de novos papéis; desenvolvimento de competências e autoconfiança em novos papéis e relações; e a reintegração na sociedade a partir de um novo esquema ou perspectiva de significado. Essas fases nem sempre ocorrem sequencialmente e algumas podem ser omitidas ou levarem mais tempo do que outras para aparecerem (CRANTON, 2006).

A partir da descrição das fases, pode-se perceber que a aprendizagem transformadora focaliza em como os adultos aprendem por meio de novos significados em suas estruturas de referências que orientarão as suas futuras ações. Portanto, há três elementos principais da teoria da aprendizagem transformadora propostos por Mezirow (1990; 2000; 2009), que são: perspectivas de significado, domínios de aprendizagem e os tipos de reflexão.

As perspectivas de significado determinam a maneira como o indivíduo enxerga o mundo, isto é, as realidades construídas. O autor identifica três perspectivas. A primeira é chamada de epistêmica e se refere aquilo que a pessoa sabe e como ela a conhece. A segunda, sócio-linguística, diz respeito às normas sociais e culturais. A terceira está relacionada à forma como a pessoa se vê como indivíduo e denominada de perspectiva de significado psicológica (MEZIROW 1990; 2000; 2009).

Mezirow (1990; 2000; 2009) propõe três domínios de aprendizagem: a) o domínio da aprendizagem instrumental se relaciona com o conhecimento empírico do paradigma positivista, cuja ação é comandada por regras técnicas; b) o domínio da aprendizagem comunicativa érelacionado com o interesse cognitivo da prática, de modo a identificar como as pessoas aprendem enquanto adultos. Envolve questões de valores, crenças e sentimentos, que estabelecem normas sociais a serem seguidas por meio de códigos simbólicos de comunicação; c) o domínio da aprendizagem emancipatório implica autorreflexão crítica, possivelmente levando a transformações dos esquemas de significado ou de suas perspectivas. Este último domínio envolve a forma como o indivíduo constrói a sua própria história, seus papéis e expectativas sociais. Destaca-se que os domínios de aprendizagem instrumental e comunicativa podem trabalhar juntos e interagir entre eles. Já o domínio emancipatório pode trabalhar em conjunto com qualquer um desses domínios, bem como pode atuar de forma independente (CRANTON, 2006; MEZIROW, 1990).

Cranton (2006) ressalta que a aquisição de conhecimento técnico por uma pessoa pode aumentar sua autoconfiança e mudar sua percepção sobre o seu lugar no mundo, obtendo uma aprendizagem emancipatória. Em alguns casos, as pessoas adquirem uma série 


\section{(9)REUNIR}

de conhecimentos instrumentais e comunicativos até que esses conhecimentos se integrem. Em outros, a aprendizagem emancipatória não ocorre, mas há apenas a aquisição de novos conhecimentos ou elaboração de conhecimentos anteriores.

O terceiro elemento da teoria da aprendizagem transformadora envolve a reflexão e é classificada emtrês tipos: conteúdo, processo e premissas. A reflexão do conteúdo se preocupa com "o que saber", a reflexão do processo com o "como saber" e a reflexão das premissas com o "por que se precisa saber". A reflexão de conteúdo, de processo e das premissas estão integradas as três perspectivas de significado, como também em todos domínios de aprendizagem (CRANTON, 2006; MEZIROW, 1990).

A teoria da aprendizagem transformadora também sofreu críticas com relação ao seu enfoque e, após algumas décadas, ainda deixa a desejar em uma série de questões como, por exemplo, qual é exatamente a perspectiva de transformação, como identificá-la e potencializá-la nos estudantes em sala de aula. Outros argumentam que as questões da transformação social não têm mais lugar em contextos de trabalho. Alguns alegam como avançar os desafios do tema para refletir criticamente que alternativas são possíveis para atuar no mundo de forma mais emancipatória, considerando experiências de vida e ao longo da vida de um ensino para a mudança a partir da equidade, justiça social, diversidade e colaboração humana, sobretudo, dos educadores no engajamento de estudantes a compreenderem melhor o mundo. No entanto, vale-se que as ideias de Mezirow continuam a moldar a educação de adultos (PARKES, 2001; KOKKO, 2015).

Não obstante, diferentes teorias de aprendizagem transformadora têm sido descritas na literatura e, na visão de Dix (2015), uma teoria integrativa dos diversos elementos que a envolva de maneira detalhada ainda não emergiu. $\mathrm{O}$ autor argumenta que os pressupostos indevidamente intelectualistas em relação à cognição dificultaram os entendimentos atuais e obscureceram a essência cognitiva e metacognitiva da aprendizagem transformadora. Em primeiro lugar, a restrição implícita de Mezirow de seu modelo socrático e habermasiano à racionalidade discursiva exclui desnecessariamente o aprendizado transformador realizado por meio de modos de cognição, metacognição e racionalidade não-discursivos. Do mesmo modo, uma concepção estreita de cognição evita que os teóricos da transformação reconheçam os papéis cognitivos essenciais em profundidade das metáforas decorrentes da experiência incorporada e sua elaboração racional em profundidade através de implicações metafóricas (DIX, 2015).

Entretanto, tais críticas não diminuem a importância da teoria de Jack Mezirow, que contribuiu para o desenvolvimento da educação de adultos. É evidente que o aprofundamento de estudos sobre a perspectiva teórica de aprendizagem é válido para ampliar a compreensão do tema tanto na área acadêmica como na profissional. Taylor (1998; 2009) destaca a existência de desafios para os educadores de adultos introduzirem a aprendizagem transformadora em sala de aula. Tais desafios incluem a necessidade de demandar mais tempo no processo de aprendizagem, a necessidade de definir grupos específicos que saibam atuar com alunos emuma maior ou menor disposição para a mudança, a necessidade de transformar sentimentos e emoções de maneira segura e não ameaçadora e, por fim, compreender o papel do próprio educador no processo de transformação. Dessa forma, percebe-se que a prática da aprendizagem transformadora, segundo Taylor (1998; 2009), tem sido minimamente investigada, é pouco conhecida e, por vezes, definida de forma inadequada. 


\section{(9)REUNIR}

A principal tarefa do professor é proporcionar um ambiente de aprendizagem, desafiando os alunos a passarem por riscos, incertezas, conduzindo-os a um mundo novo e desconhecido (KIMMEL; SEIFERT, 2009). Não obstante, a aprendizagem transformadora é uma experiência excitante e desafiadora para o aluno e para o professor. Esse processo tem efeitos mutuamente benéficos para todas as partes. Nessa perspectiva, a aprendizagem ocorre quando há uma transformação nas crenças e atitudes de ambos. O resultado deste processo pode levar a pessoa a experimentar transformação e apropriação de crenças, de forma repentina, dramática ou provocada por uma mudança lenta e progressiva. O diálogo também pode contribuir para a natureza transformadora do processo de aprendizagem (MEZIROW, 1990; 2009).

A aprendizagem transformadora demanda uma série de planejamentos e encontros acadêmicos por parte dos docentes para alinhar seus discursos e práticas do seu papel docente perante o acompanhamento da aprendizagem de seus alunos. Ao organizar tal ação de aprendizagem, os professores podem otimizar recurso, tempo e esforço de forma mais eficaz (BOONYUEN; CHARUNGKAITTIKUL; RATANA-UBOL, 2016).

Cranton (2006) explica que os professores deveriam ser levados a analisar criticamente sua prática e aumentar o senso de compreensão de si e dos outros, tornandoos capazes de se engajar na aprendizagem transformadora, que é tão crítica para um ensino bem sucedido. Ela acredita que a aprendizagem transformadora não é um processo, mas uma infinidade de processos interligados e que um programa educacional só pode ser bem sucedido se todos os alunos se beneficiarem com a implantação do programa e retirar deles o que há de essencial alcançando, assim, sua autonomia e valores andragógicos.

Considera-se que para a formação de docentes e de pesquisadores é necessário compreender os processos de aprendizagem para que se possam melhorar os métodos de ensino balizados pela andragogia, abrangendo as diferentes perspectivas teóricas da aprendizagem. Para tanto, é fundamental a compreensão de como os alunos aprendem e empreender ações para melhorar as práticas do ensino superior e tornar o aprendizado transformador para os professores e alunos.

\section{MÉTODO DE PESQUISA}

Na delimitação do percurso metodológico, optou-se pela realização de um estudo qualitativo básico (MERRIAM, 2009), que pressupõe a compreensão, à luz das perspectivas e visões de mundo de mestrandos de um programa de pós-graduação em administração, do processo de aprendizagem. Merriam (1998, p. 12) destaca três características para esse método de pesquisa: inclui descrição, interpretação e compreensão; identifica padrões recorrentes na forma de temas ou categorias e; pode delinear um processo.

A opção pela abordagem qualitativa também possibilitou maior flexibilidade do pesquisador na coleta de dados porque se utiliza de questões abertas e que pode oportunizar uma maior liberdade dos participantes, o que para Mack et al (2005) é uma das vantagens da pesquisa qualitativa.

Para a coleta dos dados, foi utilizado um roteiro de entrevista semiestruturado com 17 perguntas em torno da temática pesquisada que, conforme Godoy (2006), tem como objetivo principal captar os significados que os entrevistados atribuem às questões e situações relativas ao tema de interesse. O roteiro foi elaborado a partir de dimensões e 


\section{(9)REUNIR}

elementos constitutivos da aprendizagem transformadora propostos por Mezirow (1990; 2000; 2009). As questões serviram de base para compreender como os mestrandos aprendem. O quadro 1 apresenta as dimensões, os elementos constitutivos propostos por Mezirow e as categorias que emergiram a partir da análise das entrevistas e se configuram comos os principais significados relacionados à aprendizagem dos mestrandos. Salienta-se que as categorias emergiram a partir da análise das entrevistas.

\begin{tabular}{|c|c|c|}
\hline DIMENSÕES & $\begin{array}{l}\text { ELEMENTOS } \\
\text { CONSTITUTIVOS }\end{array}$ & CATEGORIAS \\
\hline \multirow{3}{*}{$\begin{array}{l}\text { PERSPECTIVA DE } \\
\text { SIGNIFICADO }\end{array}$} & Epistêmica & $\begin{array}{l}\text { Forma de aprender; Visão de mundo; Significado do } \\
\text { mestrado. }\end{array}$ \\
\hline & Sociolinguística & Papel do professor; Conteúdo das disciplinas. \\
\hline & Psicológica & $\begin{array}{l}\text { Consequência das mudanças; Forma de pensar e } \\
\text { agir. }\end{array}$ \\
\hline \multirow{3}{*}{$\begin{array}{l}\text { DOMÍNIOS DA } \\
\text { APRENDIZAGEM }\end{array}$} & Instrumental & Papel do mestrado na formação. \\
\hline & Comunicativo & $\begin{array}{l}\text { Impacto dos valores e sentimentos; Experiência de } \\
\text { aprendizagem. }\end{array}$ \\
\hline & Emancipatório & $\begin{array}{l}\text { Criticidade; Experiências positivas; Experiências } \\
\text { negativas. }\end{array}$ \\
\hline \multirow{3}{*}{ TIPOS DE REFLEXÃO } & Conteúdo & Prática reflexiva. \\
\hline & Processo & $\begin{array}{l}\text { Falta de reflexão no processo de autoconhecimento; } \\
\text { Maneira de refletir. }\end{array}$ \\
\hline & Premissa & Reflexão sobre as experiências vividas \\
\hline
\end{tabular}

Quadro 1: Quadro de referência para a coleta dos dados da pesquisa baseados em estudos de Mezirow (1990; 2000; 2009)

Fonte: Elaboração própria, 2013.

O contexto do estudo foi o Programa de Pós-Graduação em Administração da Universidade Federal da Paraíba, criado em 1976, um dos mais tradicionais programas de pós-graduação em administração do país, que exerce um papel relevante no contexto regional, pois contribui com a formação de mestres e, mais recentemente, implantou um curso de Doutorado com área de concentração em Administração e Sociedade. Com relação aos sujeitos da pesquisa, foram selecionados mestrandos da linha de pesquisa de marketing e tecnologia da informação que não cursaram disciplinas específicas relacionadas à aprendizagem. Foram pesquisados 10 (dez) alunos que ingressaram no curso de mestrado nos anos de 2009 e 2010 e que já estavam em fase de elaboração da dissertação, ou seja, já tinham cursado todas as disciplinas obrigatórias e eletivas do curso.

Dos dez mestrandos que participaram da pesquisa, sete são mulheres, oito são solteiros, sete apenas estudavam e três trabalhavam sem afastamento. Oito dos pesquisados residiam com as famílias e dois moravam em casa de amigos ou parentes.

A coleta dos dados foi realizada em horário previamente agendado com os participantes da pesquisa e o local escolhido pela maioria foi uma das salas de aula do prédio do PPGA/UFPB, o que favoreceu um clima agradável aos entrevistados e maior comodidade na disponibilidade de tempo. Os demais foram entrevistados em outros espaços da universidade. As entrevistas foram realizadas em 2011 e tiveram duração média de uma hora e meia. E foram gravadas em meio digital e transcritas na íntegra para eliminar as imprecisões das anotações de campo e ampliar a possibilidade de acesso público dos resultados, com elevado detalhamento (GODOI; MATTOS, 2006). 


\section{(9)REUNIR}

O processo de análise dos dados seguiu os pressupostos da análise do discurso que, conforme Roesch (2006), focaliza a variação da linguagem a fim de verificar como e quando a variação no discurso emerge e a que propósito ela serve. Por ser interpretativa, a prática da análise do discurso não pode ser reduzida a uma série de passos ou procedimentos técnicos aplicados mecanicamente, uma vez que é uma abordagem transdisciplinar ampla e teórica (GODOI, 2006).

\section{ANÁLISE E DISCUSSÃO DOS RESULTADOS}

Os mestrandos foram questionados sobre como aprendiam antes de ingressar no mestrado e como aprendem um ano após o ingresso no PPGA, que corresponde ao período de cumprimento de créditos das disciplinas. A maioria afirma o quanto o mestrado mudou a maneira como eles aprendem, uma vez que o aprendizado era mais automático, solto e superficial e como o mestrado demandou a necessidade de estudar mais em decorrência do maior grau de exigência, o que os deixou mais críticos. Também ressaltaram os aspectos que envolvem o convívio social como uma maneira de melhorar a forma como se aprende. Por outro lado, alguns citam que a maneira como eles aprendem é praticamente a mesma, pois depende muito da pessoa envolvida em buscar ou não aprender alguma coisa. E ainda há os que questionam o ritmo de estudos na busca do aprendizado.

Eu preciso ter um tempo para poder saber o que foi que eu absorvi e tem muita coisa que eu fico sem saber porque que eu fiz isso e tenho que voltar e tal. É como se desse um branco depois e não sei como eu cheguei ali. [M7]

Também tem umas que demandam mais horas de estudo, são mais pesadas, vamos dizer assim e aí você tem que correr atrás mesmo pra tentar entender inclusive coisas que você não era acostumado, que você não tinha domínio. Então você tinha que ir se aprofundar e tinha que ir buscar mesmo, correr atrás sozinho. [M8]

Nos discursos, percebe-se a utilização de palavras que caracterizam as disciplinas do curso, como "mais pesadas", "correr atrás sozinho" e que demandam dos mestrandos um autodirecionamento. Os discursos também revelaram a ausência de uma reflexão crítica sobre seu aprendizado, aquela reflexão proposta por Mezirow (1990), na qual o estudante na medida em que conhece os novos assuntos reflete sobre os mesmos. Nesse caso, nota-se a predominância do domínio instrumental, com uma preocupação mais voltada para 'o que saber', vinculado ao conteúdo da reflexão. Apesar de demonstrarem uma noção de autodirecionamento, pois tem a consciência de que a vontade de aprender depende deles, há uma ausência da parceria entre professor e aluno no processo de aprendizagem, uma vez que o aprendizado ocorre de forma solitária como revelam os relatos a seguir:

A gente, às vezes, nem aprende tanto com o professor e temos é que correr atrás mesmo dos assuntos. [M10]

(...) Acredito que ele tem que dosar essa questão da cobrança, de exigência, mas com certa flexibilidade pra que o aluno se sinta mais a vontade de aprender, de buscar coisas novas. [M8]

(...) Agora assim, tem os casos específicos que é esse caso de terrorismo que tem a questão de desestimular, né? Que em vez de você querer aprender, você fica querendo se livrar, passar, dar um jeito de conseguir aquela nota e ir embora...Tinha que ser modificada a postura de alguns professores, a visão que eles têm de mundo pra favorecer uma maior aprendizagem no mestrado, entendeu? [M9]

Os discursos revelam que o professor deveria perceber as especificidades dos alunos e entender que a maneira como eles aprendem é influenciada pelas suas características

44 


\section{(9)REUNIR}

individuais e pelo estilo de aprendizagem. A distância entre professor e aluno fica evidente quando o ambiente comportamental da aprendizagem (MERRIAM; BROCKETT, 2007) é marcado pelo "terrorismo" e o "desestímulo". Fica evidenciado que o papel dos docentes na institucionalização de um processo de aprendizagem transformadora é fundamental. Um dos princípios da educação de adultos citados por Lindeman (1926) e Knowles (1980) está ligado à parceria professor-aluno para trocar experiências que sejam significativas na aprendizagem. $O$ contexto da sala de aula e o conteúdo das disciplinas também influenciam na forma de aprender dos estudantes e no estímulo a sua participação na construção de um processo de aprendizagem que traga sentido as suas vidas. O sentido para a vida está intimamente associado ao significado do que eles aprendem no mestrado, o que está relacionado à necessidade de aprender, à orientação e à motivação para a aprendizagem, princípios da educação de adultos propostos por Knowles, Holton e Swanson (2011).

Teve disciplina que eu absorvi bastante, pois trouxe muito sentido pra minha vida. Mas já teve outras
disciplinas que eu não vi, não não agregou tanto (...) não adicionou na minha vida tanto como
acadêmico como quanto pessoa. São disciplinas que passou, eu nem tinha muita motivação pra vir pra
essa aula. [M3]
(...) Eu acho que tem umas que devem ser mais bem abordadas. A questão de personalidade do
professor, do tempo, da aplicabilidade são fatores que influenciam. Outras até funcionaram bem. [M9]

Os alunos entrevistados, de uma maneira geral, indicam um saldo positivo em relação ao conteúdo das disciplinas, porém, alguns fatores associados ao perfil do professor e o tempo limitam uma aprendizagem emancipatória, a partir da autorreflexão crítica.

(...) O que realmente eu mais consigo tirar é a capacidade de tentar ler nas entrelinhas, de crítica, de não ler apenas o que está escrito, mas tentar abstrair um pouco mais daquilo que estou estudando. Isso eu vejo que o mestrado me acrescentou. [M2]

Você passa a ser mais crítico, a observar detalhes, mais análise e o enfoque no mestrado é essa parte de metodologia, então, a minha monografia mesmo era péssima, quando a gente entra passa em um nível que fica mais crítica, você passa a ter contato com a área de pesquisa. (...) A gente começa a observar os pontos de vistas diferentes, de autores e começa a ter uma postura mais sua. A gente passa a analisar o que os outros pensavam, discordando, tendo um senso mais crítico porque a gente sabe que nem tudo a gente tem que concordar, né? [M10]

Analisando os discursos dos mestrandos acima, percebe-se que a criticidade está associada à capacidade de "ler nas entrelinhas", ou seja, perceber além do prescrito, analisar de forma mais profunda e mais acurada a partir do que foi aprendido em sala de aula. $\mathrm{O}$ contato com a pesquisa parece ser o fio condutor desse processo de transformação nos esquemas de significado, promovendo o desenvolvimento do senso crítico e de uma postura mais autônoma. Essa criticidade, como bem cita Mezirow (2000), tem que levá-los a transformações de seus esquemas de significados.

O estudo revela, assim, que a vivência das disciplinas no mestrado promove alterações nos esquemas de significado, mas não leva a uma mudança nas perspectivas de significado. Isso fica evidente quando abordados sobre a visão de mundo e eles se mostraram bem confusos em suas respostas, pois não tinham certeza se realmente os questionamentos e reflexões que passaram a fazer sobre o mundo e a si próprio levaram a uma mudança na forma de enxergar a realidade. Evidencia-se a existência da falta de maturidade, muitas vezes em virtude do ambiente em que estão inseridos, que não está 


\section{(9)REUNIR}

adequadamente voltado ao que se pressupõe da andragogia, na qual Merriam e Caffarella (1991) já afirmavam que fatores organizacionais podem facilitar ou dificultar a educação de adultos.

(...) Mas a visão de mundo eu acho que não mudou tanto não. Eu continuo vendo as coisas a minha maneira. Isso ai o mestrado não vai conseguir mudar, entendeu? A minha maneira de ver as coisas não tem como mudar através do mestrado. (...) É nesse sentido de ver as coisas mais com mais crítica, mas ai não é que mudou a minha visão de mundo. Mudou a forma como eu analiso as coisas. [M1] Não, não a forma como eu percebo o mundo, mas a forma como eu posso perceber o mundo. Vamos lá, a minha visão de mundo não foi alterada a partir do conjunto de disciplinas que nós vimos, mas a percepção de que eu posso expandir as formas que eu tenho atuais sim. [M6]

Eu não vou dizer que sou outra pessoa porque a gente nasce a pessoa de sempre né? Vai ser sempre a mesma pessoa, mas eu estou conseguindo controlar mais determinadas coisas da minha vida. E essa compreensão que agora eu tenho do mundo, da vida, das situações, essa compreensão faz com que eu consiga controlar sentimentos, emoções, saiba como fazer críticas, como dar sugestões, saiba como me comportar, eu to conseguindo controlar mais isso. [M7]

Os discursos revelam o quanto é conflitante a questão da visão de mundo, pois para alguns houve mudanças, que foram para a vida, mas fica perceptível que algumas alterações envolvem mais o comportamento e se relacionam mais a perspectiva sociolinguística e psicológica, não modificando realmente a visão de mundo em relação às suas perspectivas de significados. Chama atenção o discurso de M7, que consegue perceber mudanças em torno do senso de compreensão de si e dos outros, controlando melhor os sentimentos e emoções, o que pode ajudá-la no engajamento em torno da aprendizagem transformadora.

Outros discursos dos mestrandos entrevistados indica que as mudanças ocorridas a partir da vivência no mestrado objetivaram adequar às situações vividas no mestrado e também serviram para a vida como um todo. As mudanças, segundo os respondentes, no decorrer do tempo, foram girando em torno de toda a vida. Isso ratifica o pensamento de Taylor (2009) ao ressaltar que as pessoas lidam com a mudança de forma diferente.

Mais pra adequar a vivência e aos objetivos do mestrado porque inclusive tem muitas coisas que eu faço pro mestrado que eu particularmente acho que é desnecessário, que acho que não é relevante em um papel de aprendizagem para mim como profissional e como pessoa. [M1]

Tem me ajudado na minha vida como um todo. Tenho aprendido tanto com os professores, como com os alunos e em casa mesmo com as reflexões após as leituras dos textos (...) está me proporcionando um autoconhecimento sobre quem eu sou (...) [M3]

Por mais que essas mudanças atinjam toda a vida, não tem sido suficiente para introduzir uma aprendizagem emancipatória. Por sua vez, em relação ao impacto dos valores e sentimentos, novamente os mestrandos se mostram resistentes ao ponto de estabelecerem certo bloqueio às mudanças de seus valores e sentimentos. Logo, não ocorre o que é comentado por Mezirow (2000; 2009) a respeito da aprendizagem comunicativa, na qual as pessoas devem se envolver em seus valores e sentimentos, estabelecendo normas sociais a serem seguidas, levando-as a uma aprendizagem significativa, quando em conjunto com a instrumental.

(...) Eu assim sempre procurei ser muito fiel aos meus valores, princípios e tal, vida familiar em si, a vida social também, então, isso consequentemente, vai afetar assim a minha forma de aprender, de refletir (...) [M4] 


\section{(9)REUNIR}

(...) a emoção é algo que repercute em tudo na sua vida, né? Se você não tiver controlado isso, vai comprometer em todos os lados da sua vida, até mesmo na capacidade de você aprender, enfrentar as situações. [M7]

Não, não com relação a valores, essas coisas eu acredito que não altera, é mais com relação à visão de mundo que altera, a observar mais, a ser mais crítico como te falei. [M8]

No âmbito do conhecimento, principalmente técnico, a análise dos discursos revela o nível de empolgação dos alunos com o mestrado, contando que depois que entraram no curso houve um aprofundamento nos estudos. O que se nota pelos discursos é que eles percebem um crescimento pessoal, alterações no seu modo de ser, aumento no nível de autoconhecimento, mas de uma forma um tanto conturbada em suas "cabeças". Eles não conseguem enxergar o que contribuiu para o amadurecimento e como esse processo ocorreu. Por isso, os discursos revelam dúvidas, contradições, perturbações intrigantes a respeito da visão de mundo. Após a conclusão das disciplinas, começaram a surgir alguns questionamentos, além de uma maior clareza em torno de determinados conteúdo das disciplinas, o que contribuiu para ampliar o conhecimento sobre a administração, restrito a "pontinha do iceberg", além do nível de autoconhecimento, sobretudo, quando vivenciaram experiências que os marcaram durante o mestrado.

Todos os conceitozinhos, tudo que você imaginar de administração, dos livros básicos e tal eu sabia tudo, tinha tudo decoradozinho e tal, vivenciado até nas empresas. Depois que eu entrei no mestrado, logo nos primeiros dias de aula eu vi que que aquilo ali era só a pontinha do iceberg, entendeu? [M1] Depois que entrei na graduação eu aprendi muita coisa, mas era tipo aquela coisa o professor ensinava e você assimilava, respondia uma prova, fazia um trabalho e parece que aquilo eu guardava na minha cabeça e pronto. E a partir do mestrado eu consegui juntar, fazer ponte do que eu tava aprendendo, do que eu sabia e não sabia e hoje já consigo utilizar de forma mais ampla, de visualizar todo o meu conhecimento. [M2]

Quando eu entrei no mestrado eu tava verde e no decorrer do mestrado eu fui assimilando novas maneiras de aprender ou de, não só de aprender, mas de me desenvolver (...) Pronto, acredito que essa foi minha, uma das principais mudanças como estudante, aprender a pesquisar. [M3]

Quando abordados a respeito de suas experiências, a maioria ressaltou o valor das atividades compartilhadas em grupo, que foram enriquecedoras no seu aprendizado. Contudo, salientaram a questão do comprometimento que os demais deveriam ter para que o trabalho em equipe alcançasse êxito. Em contrapartida, alguns relataram também que as experiências individuais contribuíram para o crescimento pessoal e profissional. $O$ uso da palavra "vazio" no discurso de M5 chama atenção porque revela um nível de consciência da importância de buscar o conhecimento antes de compartilhá-lo com o grupo e aprender. Ela só se torna coletiva quando o mestrando entra no ritmo e, como afirmou M6, é preciso manter o ritmo e assumir um papel mais ativo e participativo no processo.

Eu gosto de trabalhar em grupo, só que o grupo tem (...) duas fases, não basta o grupo se juntar pra aprender, os indivíduos tem que antes fazer algum esforço só, então, o grupo se junta e aprende porque se todo mundo vier vazio, vai sair todo mundo vazio.[M5]

Ocorria principalmente em estudos mesmo, nas discussões em sala de aula porque você sabe que no mestrado nas aulas você não fica como ouvinte, de forma passiva, você tem que participar (...) Quando você estuda em grupo tem o risco de se dispersar e conversar coisas que não tem nada a ver. Então eu sempre tinha esse receio de estudar em grupo por conta disso. Mas no mestrado não foi assim, quando o grupo ia estudar realmente a gente estudava. [M6] 
No que se refere à prática reflexiva, foi questionado se o Mestrado permite tempo para os alunos refletirem e verificou-se que não permite, pois eles relataram que tudo é muito corrido e durante as disciplinas há a necessidade de uma resposta rápida quanto às atividades, não tendo tempo para a reflexão. Apesar do volume de atividades em um mestrado acadêmico demandarem tempo e dedicação, é fundamental discutir os métodos e técnicas de ensino para estimular a reflexão e ajudar os alunos na introdução de um processo de aprendizagem mais significativo, atendendo as situações contextuais necessárias de suas vidas (NYE; CLARCK, 2016; WESTOBY; LYONS, 2017), tornando o mestrado determinante para a carreira acadêmico-profissional e pessoal. Porém, os resultados também suscitam uma reflexão sobre o perfil desses alunos que estão ingressando em uma Pós-graduação. Será que eles apresentam a maturidade necessária e a capacidade de autodirecionar a sua aprendizagem? Percebe-se que o aluno ingressa cada vez mais jovem na pós-graduação e isso pode trazer implicações no processo de aprendizagem, sobretudo quando balizado pela aprendizagem transformadora, que demanda autonomia, capacidade de reflexão e autodirecionamento do aluno.

\footnotetext{
Eu acho que eu não utilizei tudo, mas eu não sei se isso foi uma falha minha ou se foi uma falha geral do Programa. Eu acho que durante as disciplinas não dá pra refletir tanto assim não porque era muita coisa junta, algumas variadas e a reflexão eu vim ter pode ter vindo agora, de alguns insights que eu não tive tempo de fazer na época que estava pagando a disciplina. Se eu tivesse feito isso na época eu acho que eu teria aproveitado muito mais. E hoje esses insights fazem um delay imenso e eu não consigo capturar tudo o que eu vi. [M2]

Então, eu tava refletindo sobre isso, o quão importante essa pressão, essa coisa de prazo e a carga de atividade e tarefa e tal porque isso contribui para o amadurecimento. (...) essa contribuição para o amadurecimento pessoal eu acho que é uma um grande insight, uma grande sacada que é uma pósgraduação nesse nível (...) [M6]

Acho que o mestrado permite pouco tempo para reflexão porque é muito corrido, quando você menos espera você já acabou. Então você tem uma carga muito grande de atividades, você tem um excesso de conhecimento muito intenso que às vezes você não tem muito tempo pra parar e refletir. Então, não dar pra pensar muito, você tem que agir rápido. Eu acho que a reflexão vem no banho, vem em momentos de lazer que você tá com sua família, que você acaba que assimilando as coisas que você aprendeu. [M10]
}

Ficou evidenciada a ausência de uma reflexão crítica, pois efetivamente o que se tem visto foi uma reflexão em nível inicial, principalmente sobre a ação. A falta de tempo para reflexão denota justamente que a reflexão só ocorre após e não na ação. Será que as disciplinas do curso não estimulam os alunos a refletirem no momento da aula, no questionamento do professor, no argumento de um aluno, nas contradições sobre o significado de conceitos, abordagens, visões de mundo dos autores?

Apesar de alguns terem até dito que tomou um posicionamento mais crítico, esses posicionamentos estavam voltados mais às questões técnicas, reduzindo-se aos estudos. 0 tipo de reflexão 'premissa' abordada por Mezirow (1990), que se atenta ao por que se precisa saber, quase não foi observada no discurso dos mestrandos pesquisados, pois muitos, como já comentado, preocupam-se com'o que' e 'como saber'. Quando perguntados como têm refletido sobre o que aprenderam no mestrado, ficou evidenciada a falta de reflexão, até mesmo de um autoconhecimento a partir do que se tem vivenciado no mestrado. Percebe-se pelo discurso a seguir uma insegurança em relação a forma de refletir. 


\section{(9)REUNIR}

É fundamental a continuidade do processo de reflexão, pois é um processo contínuo na busca da melhoria como pessoa. Porém, conforme Mezirow (2000), as reflexões precisam iniciar durante o período que a pessoa está vivenciando, ou seja, a reflexão deve ocorrer na ação e ir aprimorando o processo de aprendizagem para que seja transformador.

Cara eu nunca pensei sobre isso. Deixa eu pensar... Pra mim está muito em cima, então, é talvez eu veja mais diferença quando eu tiver no mercado mesmo, quando eu tiver é é trabalhando. Enfim, daqui a um ano quando tudo isso tiver mais maduro na minha mente [M5]

Percebe-se que os alunos gostariam que o aprendizado no mestrado fosse mais prazeroso, mas as emoções vividas ao longo do primeiro ano do curso provocaram sofrimentos e momentos difíceis. Para a maturidade do aluno, é essencial tirar proveito de experiências que causam sofrimento. Contudo, o que alguns mestrandos questionaram é esse processo contínuo de cobrança, de estresse, que torna o processo de aprendizagem mediado pelo sofrimento. Essas situações levaram os alunos a refletirem sobre as implicações das experiências vividas no curso para as suas vidas.

(...) Eu sempre fui uma pessoa de estudar, gosto muito de estudar, só que na minha opinião estudar é algo que faço que é prazeroso pra mim. Não é estudar em cima de estresse, de prazo, de tempo. (...) depois que entrei no mestrado (...) minha carga de estudo aumentou, quer dizer, acho que triplicou, ne? E essa carga de estudo que eu tive acabou, tipo assim, modificando muita coisa na minha vida. $E$ assim, o aprendizado passou a ser um sofrimento. (...) antes eu tinha uma situação de mais leveza com meus estudos e agora não tenho mais porque agora estou me sobrecarregando demais e dá vontade de fugir de determinadas situações. (...) eu aprendi aqui que eu não posso tá me dedicando só a uma coisa, eu tenho uma vida pra viver. Eu tenho amigos, eu tenho família, tenho meus compromissos, sonhos [M7]

Assim, por meio das experiências relatadas pelos mestrandos, percebe-se que são múltiplas vivências que, em alguns momentos, eles enxergam a relevância de situações tidas no mestrado e em outros momentos eles são marcados por experiências angustiantes e questionam se o processo precisa ser conduzido de forma dolorosa e sofrido.

Tomando como referência o processo de análise dos discursos dos mestrandos sobre as experiências de aprendizagem vivenciadas no mestrado, foram identificados alguns significados que subsidiam a compreensão do processo à da teoria da aprendizagem transformadora. A seguir, apresenta-se o quadro 2 sobre os significados e transformações nas dimensões da aprendizagem transformadora.

\begin{tabular}{|c|c|c|}
\hline DIMENSÕES & SIGNIFICADOS & TRANSFORMAÇÕES \\
\hline \multirow{4}{*}{$\begin{array}{l}\text { PERSPECTIVA DE } \\
\text { SIGNIFICADO }\end{array}$} & Forma de aprender & $\begin{array}{l}\text { Passaram a ser autodirecionados e críticos em } \\
\text { relação ao conteúdo da aprendizagem. }\end{array}$ \\
\hline & Visão de mundo & $\begin{array}{l}\text { Houve mudança nos esquemas de significado, mas } \\
\text { não houve alteração na perspectiva de significado. }\end{array}$ \\
\hline & Significado do mestrado & $\begin{array}{l}\text { Determinante em suas vidas, pois ajudou no } \\
\text { direcionamento de seu desenvolvimento } \\
\text { profissional. }\end{array}$ \\
\hline & Papel do professor & $\begin{array}{l}\text { Sentiram a necessidade de fortalecer a parceria } \\
\text { entre aluno e professor para compartilhar } \\
\text { experiências significativas para ambos. }\end{array}$ \\
\hline
\end{tabular}




\begin{tabular}{|c|c|c|}
\hline & Conteúdo das disciplinas & $\begin{array}{l}\text { Influenciou a forma de aprender e estimular a } \\
\text { participação no processo de aprendizagem. }\end{array}$ \\
\hline & $\begin{array}{l}\text { Consequência das } \\
\text { mudanças }\end{array}$ & $\begin{array}{l}\text { As mudanças individuais decorrentes da participação } \\
\text { no mestrado não possibilitaram a transformação nas } \\
\text { perspectivas de significado. }\end{array}$ \\
\hline & Forma de pensar e agir & $\begin{array}{c}\text { É inconsciente e dificulta a mudança na perspectiva } \\
\text { de significado. }\end{array}$ \\
\hline \multirow{6}{*}{$\begin{array}{l}\text { DOMÍNIOS DA } \\
\text { APRENDIZAGEM }\end{array}$} & $\begin{array}{l}\text { Papel do mestrado na } \\
\text { formação }\end{array}$ & $\begin{array}{l}\text { Direcionado mais para a dimensão acadêmica da } \\
\text { formação. }\end{array}$ \\
\hline & $\begin{array}{l}\text { Impacto dos valores e } \\
\text { sentimentos }\end{array}$ & $\begin{array}{l}\text { Pequena em função do nível de resistência dos } \\
\text { alunos. }\end{array}$ \\
\hline & $\begin{array}{l}\text { Experiência de } \\
\text { aprendizagem }\end{array}$ & $\begin{array}{c}\text { Maior valorização do trabalho em grupo e o } \\
\text { comprometimento de todos na realização das } \\
\text { atividades. }\end{array}$ \\
\hline & Criticidade & $\begin{array}{l}\text { Desenvolvimento da capacidade de 'ler nas } \\
\text { entrelinhas', ir além do prescrito, analisando de } \\
\text { forma mais profunda e acurada a partir do que foi } \\
\text { aprendido em sala de aula. }\end{array}$ \\
\hline & Experiências positivas & Contribuição para a sua formação profissional. \\
\hline & Experiências negativas & $\begin{array}{c}\text { Dificuldade de lidar com a pressão sofrida em } \\
\text { relação ao volume de leitura, a sobrecarga de tarefas } \\
\text { e a didática de alguns professores que dificulta a } \\
\text { aprendizagem. }\end{array}$ \\
\hline \multirow{3}{*}{ TIPOS DE REFLEXÃO } & Prática reflexiva & $\begin{array}{l}\text { Limitada pela correria das disciplinas e a necessidade } \\
\text { de cumprir as exigências do curso. }\end{array}$ \\
\hline & Reflexão na ação & $\begin{array}{c}\text { Dificuldade de reflexão pela ausência sobre o 'como' } \\
\text { eles vivenciam e passam a conhecer as experiências } \\
\text { vivenciadas no mestrado. Ocorre mais a reflexão } \\
\text { sobre a ação do que a reflexão na ação. }\end{array}$ \\
\hline & $\begin{array}{l}\text { Reflexão sobre as } \\
\text { experiências vividas }\end{array}$ & $\begin{array}{l}\text { Frágil em decorrência do baixo nível de maturidade e } \\
\text { não conduz a autorreflexão crítica. }\end{array}$ \\
\hline
\end{tabular}

Quadro 2: Significados e transformações nas dimensões da aprendizagem transformadora

Fonte: Elaboração própria, 2013.

Portanto, analisando os relatos dos entrevistados em consonância aos aspectos teóricos, constatou-se que a experiência vivenciada pelos mestrandos promoveu mudanças em suas vidas, alterando seus esquemas de significado. Eles sentem a importância do mestrado para sua formação, mas por várias dificuldades e limitações como, por exemplo, os próprios métodos de ensino dos professores e o próprio nível de maturidade e autoconhecimento dos alunos, fazem com que o processo de aprendizagem desses mestrandos não seja emancipatório e nem promova uma autorreflexão crítica.

\section{CONSIDERAÇÕES FINAIS}

Este estudo investigou o processo de aprendizagem transformadora de mestrandos da linha de pesquisa de Marketing e Tecnologia da Informação do PPGA/UFPB. Analisar o processo de aprendizagem transformadora é complexo porque o processo de transformação envolve um conjunto de elementos associados às perspectivas de significado, aos domínios de aprendizagem e à reflexão. 


\section{(9)REUNIR}

Os resultados da pesquisa indicam a presença de alguns elementos constitutivos da aprendizagem transformadora, mas não se pode concluir que o mestrado promoveu uma aprendizagem transformadora nos alunos. Aspectos como o tempo de permanência no curso, a maturidade, o nível de autodirecionamento dos alunos, além de questões vinculadas ao ambiente de aprendizagem e o relacionamento entre os docentes e os mestrandos, atuam como fatores mediadores do processo de aprendizagem.

Percebe-se, a partir da análise dos resultados, um baixo nível de maturidade dos alunos, que ao ingressar no mestrado passaram a vivenciar experiências mediadas pela cobrança, pelo sofrimento e pela tensão, sobretudo na relação com os docentes. Os professores precisam avaliar a forma como conduzem o processo de aprendizagem e empreenderem ações que estimulem a capacidade de reflexão dos alunos.

O processo de aprendizagem transformadora demanda tempo para reflexão e maturidade das pessoas. $O$ estudo revela que analisar essa perspectiva de aprendizagem na metade do curso dificulta a análise de seus elementos constitutivos, pois a caracterização efetiva de que o aprendizado foi emancipatório apenas se torna possível após a conclusão do curso a partir das reflexões que o aluno realiza acerca de suas experiências vividas no ambiente de aprendizagem.

Entretanto, os resultados revelados no estudo sugerem a necessidade dos programas de pós-graduação refletirem sobre a necessidade de implantarem ações que promovam o desenvolvimento de competências para a formação do professor e do pesquisador, a partir de uma avaliação sobre as perspectivas de significado, os domínios de aprendizagem e os tipos de reflexão que podem ser incorporados no processo de ensino, nas relações professor-aluno e também a criação de um ambiente de aprendizagem que não considere apenas a dimensão física, mas também a comportamental, a social, a tecnológica e a política.

Essa reflexão sobre os processos de aprendizagem à luz da aprendizagem transformadora pode contribuir para melhorias no processo de formação na pós-graduação, uma vez que tal perspectiva teórica de aprendizagem pode ser um caminho para avaliar o impacto de um programa de pós-graduação nas perspectivas de significado em nível pessoal e social.

O estudo realizado com os alunos pode ampliar a compreensão desse tipo de aprendizagem, sobretudo, na esfera da pós-graduação para que docentes e discentes possam refletir sobre seus papéis no processo de ensino e aprendizagem. As futuras pesquisas podem delinear possíveis caminhos para o processo formativo ser transformador, considerando o olhar do discente, daquele que vivencia o ensino ofertado e, assim, aproximar a realidade do alunado com o contexto acadêmico, social e empresarial.

\section{REFERÊNCIAS}

BEAVERS, A. Teachers As Learners: Implications Of Adult Education For Professional Development. Journal of College Teaching and Learning, v. 6,n.7,Nov 2009.

BOONYUEN, S. CHARUNGKAITTIKUL, Suwithida. RATANA-UBOL, Archanya. Integrating transformative learning and action learning approaches to enhance ethical leadership for supervisors in the hotel business. SHS Web of Conferences, n 26, 2016. 


\section{(9REUNIR}

CHAPMAN, S. A. A Theory of Curriculum Development in the Professions: An Integration of Mezirow's Transformative Learning Theory with Schwab's Deliberative Curriculum Theory. (a dissertation) 415 pages. Submitted to the Ph.D. in Leadership \& Change Program of Antioch University (USA) January, 2007.

CLARKE, M.; BUTCHER, D. Reconciling Hierarchy and Democracy: The Value of Management Learning. Management Learning, v. 37, n. 3, p. 313-333, sep. 2006.

CLIFFORD, V. MONTGOMERY, Catherine. Transformative Learning Through Internationalization of the Curriculum in Higher Education. Journal of Transformative Education. Vol. 13(1) SAGE, 2015.

CRANTON, P. Understanding and promoting transformative learning: a guide for educators of adults. San Francisco: Jossey-Bass Publishers. Second edition. 2006.

DEWEY, J. The educational situation: as concerns the elementary school. Curriculum Studies, v. 33, n. 4, 2001.

DIX, M. The Cognitive Spectrum of Transformative Learning. Journal of Transformative Education. Vol. 14(2), SAGE, 2016.

FREIRE, P. Pedagogia do oprimido. 10 ed. Rio de Janeiro: Paz e Terra, 1981.

GODOI, C. K. Perspectivas de análise do discurso nos estudos organizacionais. In: GODOI, C. K; MELLO, R.B.; SILVA. A.B. (org.). Pesquisa qualitativa em estudos organizacionais: paradigmas, estratégias e métodos. São Paulo: Saraiva, 2006.

GODOI, C. K.; MATTOS, P.L.C.L. Entrevista qualitativa: instrumento de pesquisa e evento dialógico. In: GODOI, C. K; MELLO, R.B.; SILVA. A.B. (org.). Pesquisa qualitativa em estudos organizacionais: paradigmas, estratégias e métodos. São Paulo: Saraiva, 2006.

GODOY, A. S. Estudo de caso qualitativo. In: GODOI, Christiane Kleinubing; MELLO, Bandeira de.; SILVA, Anielson Barbosa da.(org.). Pesquisa qualitativa em estudos organizacionais: paradigmas, estratégias e métodos. São Paulo: Saraiva, 2006.

ILLERIS, K. Workplace learning and learning theory. Journal of Workplace Learning; v. 15, n. 4, p. 167-178, 2003.

JOUBERT, J.; SLABBERT, J. Facilitating transformative learning: supporting students experiencing unique challenges. Support for Learning. Volume 32. Number 2. 2017.

KIMMEL, J. C.; SEIFERT, V. M. Transforming Learning Through Two Pair of Eyes .Journal of College Teaching and Learning, v. 6, n. 8,p. 37-44, Dec. 2009. 


\section{(9REUNIR}

KNOWLES, M. S, HOLTON, E. F.; SWANSON, R. A. The adult learner: The definitive classic in adult education and human resource development. 7th ed. London: Elsevier. 2011.

KNOWLES, M. S. The modern practice of adult education: from pedagogy to andragogy. Cambridge Adult Education, 1980.

KOKKOS, $\mathrm{A}$; et al. Celebrating 40 Years of Transformative Learning. Journal of Transformative Education, Vol. 13(4), SAGE 2015.

KRAMER, J. A Dewey an Reflection: The Potential of Hospitality and Movement in the Classroom. Chapter 6, Hospitality and Movement. Curriculum and Teaching Dialogue. Volume 18, Numbers 1 \& 2, pp. 75-87, 2016.

LEE, K.; BRETT, C. Dialogic understanding of teachers' online transformative learning: A qualitative case study of teacher discussions in a graduate-level online course. Teaching and Teacher Education. Ed 46, 2015.

LIMA, T. B. de. Estratégias de Ensino Balizadas pela Aprendizagem em Ação: Um Estudo de Caso no Curso de Graduação em Administração da Universidade Federal da Paraíba. 221f. Dissertação (Mestrado em Administração) - Programa de Pós-Graduação em Administração, UFPB, João Pessoa - PB, 2011.

LINDEMAN, E. C. The meaning of Adult Education. New Republic, INC. New York, 1926.

LONIE, J. M. DESAI K. R. Using transformative learning theory to develop metacognitive and self-reflective skills in pharmacy students: A primer for pharmacy educators. Currents in Pharmacy Teaching and Learning ed 7, Elsevier, 2015.

MACK, N.; WOODSONG, C. MACQUEEN, Kathleen M. GUEST, Greg. NAMEY, Emily. Qualitative Research Methods: a data collector's field guide. Family Health International, 2005.

MERRIAM, S. B.; BROCKETT, R. G. The profession and practice of adult learning: an introduction. San Francisco: Jossey-Bass, 2007.

MERRIAM, S. B.; CAFFARELLA, R. S. Learning Adulthood: a comprehensive guide. San Francisco: Jossey-Bass, 1991.

MERRIAM, S. B. Qualitative Research: a guide to design and interpretation. San Francisco: Jossey-Bass, 2009.

MERRIAM, S. B. Qualitative Research and Case Study Applications in Education. San Francisco (CA): Jossey-Bass, 1998. 


\section{(9REUNIR}

MEZIROW, J. \& ASSOCIATES. Fostering critical reflection in adulthood: A guide to transformative and emancipatory learning. San Francisco, California. Jossey-Bass. 1990.

MEZIROW, J. Learning to think like an adult: Core concepts of transformation theory. In: MEZIROW, J. \& Associates (Eds). Learning as transformation: Critical perspectives on a theory in progress. San Francisco, CA. Jossey-Bass. 2000.

MEZIROW, J.; TAYLOR, E. W. \& ASSOCIATES. Transformative Learning in Practice: Insights from community, workplace and higher education. San Francisco, CA. Jossey-Bass. 2009.

MCALLISTER, M. Exploring transformative learning and the courage to teach a values based curriculum. Nurse Education in Practice, ed 15, 2015.

NYE, A.; CLARK, J. "Being and Becoming" a Researcher: Building a Reflective Environment to Create a Transformative Learning Experience for Undergraduate Students. Journal of Transformative Education. Vol. 14(4) SAGE, 2016.

PARKES, D. About Adult Education - Transformative Learning. Journal of Workplace Learning, v. 13,n. 4, p. 182-183, 2001.

PATTERSON, B. A. B. et al. Transformative Learning: A Case for Using Grounded Theory as an Assessment Analytic. Teaching Theology \& Religion, Volume 18, Issue 4, October 2015.

PERCY, R. The contribution of transformative learning theory to the practice of participatory research and extension: Theoretical reflections. Agriculture and Human Values, 2005.

ROESCH, S. M. A. Projetos de estágio e de pesquisa em administração: guia para estágios, trabalhos de conclusão, dissertações e estudo de caso. 3 ed. São Paulo: Atlas, 2006.

TAYLOR, E. W. The theory and practice of transformative learning: a critical review. Institution Eric Clearinghouse on Adult, Career and Vocational Education, Information series, n. 374, Columbus, Ohio State University, 1998.

TAYLOR, E. W. Fostering Transformative Learning. In: MEZIROW, J.; TAYLOR, E. W. \& ASSOCIATES. Transformative Learning in Practice: Insights from community, workplace and higher education. San Francisco, CA: Jossey-Bass, 2009.

WESTOBY, P.; LYONS, K. The Place of Social Learning and Social Movement in Transformative Learning: A Case Study of Sustainability Schools in Uganda. Journal of Transformative Education. Vol. 15(3), SAGE, 2017. 